\title{
An Observation of Marangoni Effect and Electric Oscillation Phenomena in an Oil-Water Interface
}

\author{
Toshiyuki Nonaka, Youichi Iyoku* and Mutsumi Suzuki
}

Dept. of Biochemistry and Engineering, Tohoku University, Sendai 980

\begin{abstract}
Key Words : Marangoni Effect, Taste Sensor, Interface Phenomena
Interface phenomena in an electrically oscillating oil-water system, which was reported as a novel taste sensor, is investigated by Schlieren photographs. It is shown that the oscillation is caused by Marangoni ef fect in an inclined interface. It depends only on the physico-chemical properties of the system and not on the taste nor on the chemical reactivities.
\end{abstract}

* SHOWA SHELL SEKIYU K.K.

\section{粉粒流動層内の微粒子帯留状況の検討 ${ }^{\dagger}$}

\section{中川紳好・古川 純 $^{*} \cdot$ 佐藤 武 $^{* *} \cdot$ 加藤邦夫 \\ 群馬大学工学部 生物化学工学科 ${ }^{\dagger \dagger}$}

先に著者らは粉粒流動層における微粒子の滞留時間分 布を残余濃度曲線法を用いて測定し，滞留時間に対する 諸因子の影響を調べ, 微粒子の平均帯留時間は (1) 微粒 子平均径の減少とともに増加すること, (2) ガスの平均 滞留時間に相当する理論平均滞留時間の150～500倍も大 きいことなどを明らかにしだ”。実際の工業プロセスへ の応用において, 微粒子の長い滞留は, 微粒子利用率を 高くできるという利点になる反面, 非常に細かい微粒子 は層内に残留してしまう可能性があるてとをあ暗示してい る. また, 比較的広い粒径分布の微粒子を利用する場合, 粒径ごとの滞留時間分布を明らかにすることが必要にな ってくると考えられる. 従って実際のプロセスへの応用 を検討する上で，乙のような微粒子の残留や層内帯留の 詳細を調べることは, 重要である. しかしながら, 前報 で用いた残余濃度曲線法では層内の初期微粒子濃度（初 期微粒子量 / 媒体粒子量) を明らかにできないため, 微 粒子の層内残留や，粒径でとの滞留状況を明らかにする ことが困難であった。

著者らは, 新たに微粒子供給を回分式で行い, 初期微

\footnotetext{
† 1993年 9 月 2 日受理 ; 化学工学会第26回秋季大会 (京都, 1993年 9 月30日) にて発表

†七 376 桐生市天神町 1-5-1

* 大日本インキ化学工業 (株)

** 利根実業高校
}

粒子濃度を明確にして微粒子の層内滞留状況の詳細を調 ベた.

\section{実験装置および方法}

実験装置の概略を Fig. 1 亿示す。流動層は内径 100 $\mathrm{mm}$, 高さ $0.60 \mathrm{~m}$ のアクリル樹脂製円筒である. 分散板 や筒内への金網リングの充塤などは前報 ${ }^{1)}$ と同様にした. 流動化ガスには相対湿度を $50 \%$ に調節した空気を用いた。

洗浄, 乾燥後の媒体粒子 (球状活性アルミナ, $d_{c p}=$ $\left.400 \mu \mathrm{m}, U_{t}=1.57 \mathrm{~m} / \mathrm{s}\right) 2500 \mathrm{~g}$ に微粒子を所定量混合し, 層内に入れ (静止層高 $0.39 \mathrm{~m}$ ), 瞬時にガスを供給して 流動化を開始させた. 空塔基準ガス速度は $0.27 \mathrm{~m} / \mathrm{s}$ で, このときの層高は $0.55 \mathrm{~m}$ であった. 流動化開始後, 排出 してくる微粒子をバッグフィルターで捕集して, 排出速 度を連続的に測定した，微粒子としては平均径（体積基 準 ) $5 \mu \mathrm{m}$ の重質 $\mathrm{CaCO}_{3}$, 平均径 (体積基準) $1 \sim 16 \mu \mathrm{m}$ の $\mathrm{Al}_{2} \mathrm{O}_{3}$ を用いた。 乙れらの粒子密度およびメ一カーカ タログから得た累積体積分率 $97 \%$ における粒子径をTable 1 亿示す.

微粒子の層内平均滞留時間 $\theta$ はその排出速度 $F_{f p}$ を用 いて，次式で与えられる.

$$
\theta=\left(1 / W_{f}\right) \int_{0}^{\infty} t F_{f p} d t
$$

本実験の場合，捕集開始後 1 時間でも排出されない微 粒子があったが，乙れらは実用上層内に蓄積するもの之 判断し, 供給微粒子量 $W_{f}$ の代りに捕集時間 $t_{I}$ までの捕 
Table 1 Ratio of fine particles remaind in the bed and average residence time of the fine particles based on the $0.5 \mathrm{~h}$ or $1 \mathrm{~h}$ operation. $\left(U_{o}=0.27 \mathrm{~m} / \mathrm{s}, L_{m f}=0.39\right.$, coarse particle; $\mathrm{Al}_{2} \mathrm{O}_{3}$ of $d_{c p}=400 \mu \mathrm{m}$ )

\begin{tabular}{|c|c|c|c|c|}
\hline Particle & $d_{f p}(* *)[\mu \mathrm{m}]$ & $W_{f} / W_{c}[-]$ & $F R_{1}$ or $F R_{0.5}^{*}[-]$ & $\theta_{e 1}$ or $\theta_{e 0.5}{ }^{*}[\mathrm{~s}]$ \\
\hline \multirow{6}{*}{$\begin{array}{c}\mathrm{CaCO}_{3} \\
\left(\rho_{p}=2350 \mathrm{~kg} / \mathrm{m}^{3}\right)\end{array}$} & \multirow{6}{*}{5} & 0.020 & 0.220 & 605 \\
\hline & & 0.015 & 0.244 & 437 \\
\hline & & 0.010 & 0.228 & 400 \\
\hline & & 0.005 & 0.197 & 221 \\
\hline & & 0.003 & 0.240 & 316 \\
\hline & & 0.001 & 0.213 & 346 \\
\hline \multirow{5}{*}{$\begin{array}{c}\mathrm{Al}_{2} \mathrm{O}_{3} \\
\left(\rho_{p}=3980 \mathrm{~kg} / \mathrm{m}^{3}\right)\end{array}$} & $1(1.99)$ & \multirow{6}{*}{0.005} & 0.941 & 1193 \\
\hline & $3(4.76)$ & & 0.126 & 704 \\
\hline & 5 & & 0.223 & 432 \\
\hline & $6.3(9.58)$ & & 0.059 & 166 \\
\hline & $10(13.9)$ & & $0.074^{*}$ & $67^{*}$ \\
\hline & $16(20.4)$ & & $0.051^{*}$ & $44^{*}$ \\
\hline
\end{tabular}

* value obtained from $0.5 \mathrm{~h}$ operation.

** diameter at $97 \%$ of cumulative volume

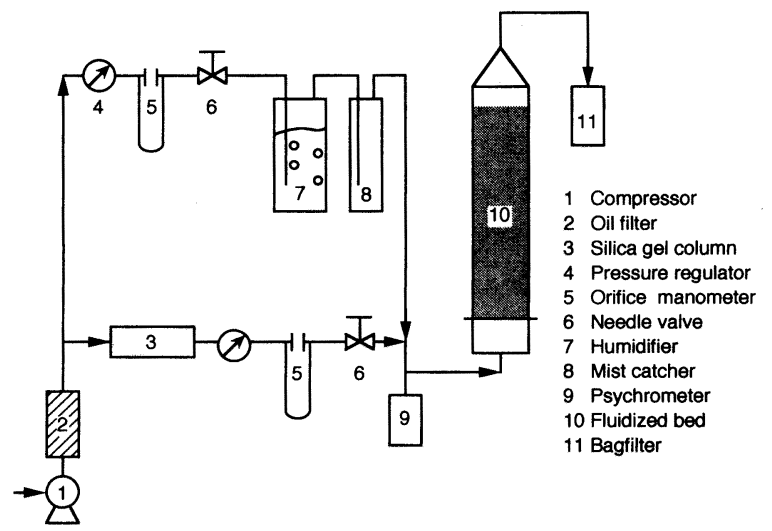

Fig. 1 Schematic diagram of the experimental apparatus

集微粒子量 $W_{e}$ を用い，次式より捕集微粒子に対する平 均滞留時間 $\theta_{e}$ を求めた.

$$
\theta_{e I}=\left(1 / W_{B}\right) \sum_{i=0}^{I}\left(t_{i} F_{f p i} \Delta t_{i}\right)
$$

また, 次式より層内微粒子残存率 $F R_{I}$ を求めた.

$$
F R_{I}=\left(W_{f}-W_{e}\right) / W_{f}
$$

実験では, 初期微粒子濃度 $W_{f} / W_{c}$, 微粒子平均径亡 $\theta_{e I}$, 微粒子残存率 $F R_{I}$ との関係を調べた.さらに, 排 出粒子の粒度分布を光透過式粒度分布測定器 (セイシン 企業, SKN 500 )で測定した. また，層内媒体粒子表面の SEM 観察をも行った.

\section{実験結果および考察}

\section{1）初期微粒子濃度の影響}

平均径 $5 \mu \mathrm{m} の \mathrm{CaCO}_{3}$ を用いて測定した, 微粒子排出速 度 $F_{f p}$ に対する初期微粒子濃度 $W_{f} / W_{c}$ の影響を Fig. 2 に示 す. $F_{f p}$ は $W_{f} / W_{c}$ の増大ととあに大きくなる傾向を示し，ま

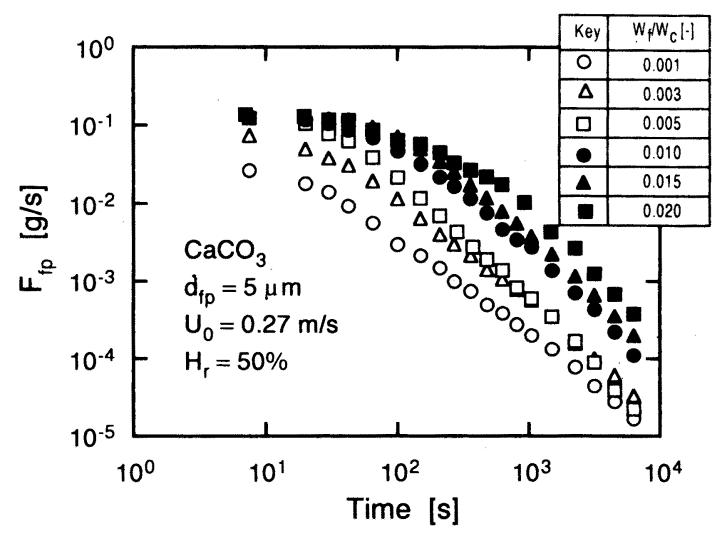

Fig. 2 Effect of initial fine particle concentration on the elutriation rate of fine particles

た時間の進行とともに減少していることがわかる．Fig. 3 亿, 流動化開始後 $7.5 \mathrm{~s}$ で求めた初期微粒子排出速度 $F_{f p_{0}}$ と $W_{f} / W_{c}$ との関係を示す. $W_{f} / W_{c}$ が 0.005 以下では, $F_{f p o}$ は $W_{f} / W_{c}$ にほぼ比例して増加しているが, $W_{f} / W_{c}$ が 0.005 より大きくなると $F_{f p_{0}}$ は打よそ $0.13 \mathrm{~g} / \mathrm{s}$ 亿頭打 ちになっているてとが分る.

捕集時間 0.5 時間あるいは 1 時間で求めた層内微粒子 残存率 ( $F R_{0.5}$ あるいは $\left.F R_{1}\right)$ 之捕集量基準の平均滞留時 間 $\left(\theta_{e 0.5}\right.$ あるいは $\left.\theta_{e 1}\right)$ をTable 1 亿示す. 平均径 $5 \mu \mathrm{m}$ の $\mathrm{CaCO}_{3}$ の場合, $F R_{1}$ は初期微粒子濃度に関わらずお よそ 0.2 と一定であった. 後の結果から分るように，粒 子径の小さい成分が残留したあの之考えられる。 また， $\theta_{e 1}$ は $W_{f} / W_{c}$ が 0.005 以上では $W_{f} / W_{c}$ の増加とともに 増加する傾向を示した。このととは，Fig.2で見られた 


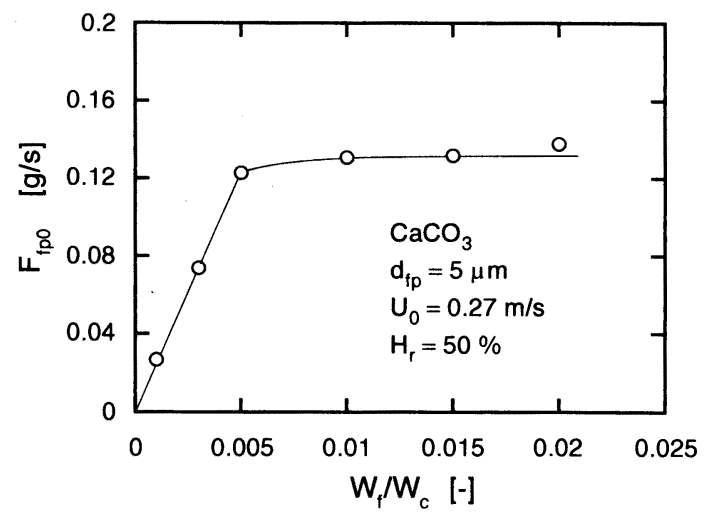

Fig. 3 Effect of initial fine particle concentration on the initial elutriation rate measured at $t=7.5 \mathrm{~s}$

ように，乙の $W_{f} / W_{c}$ では初期排出速度が頭打ちになっ た結果と考えられる．こ.の粒子の場合， $W_{f} / W_{c}$ が 0.005 より大きい場合と小さい場合とでは微粒子の層内滞留状 況が異なっていると考えられる. 層内では微粒子は媒体 粒子表面に付着していることが考えられるが, 微粒子濃 度が大き過ぎると，付着しきれずに残った微粒子は凝集 体を作っていることが予想される.

\section{2）微粒子平均径の影響}

平均径 1 $16 \mu \mathrm{m}$ の $\mathrm{Al}_{2} \mathrm{O}_{3}$ を用いて測定した, 微粒子 排出速度に対する微粒子平均径の影響を Fig. 4 亿示す. 平均径が大きいほよ゙流動化開始直後の初期排出速度が大 きく, また, 時間の経過に伴う排出速度の減衰は微粒子 平均経の減少とともに緩やかになった。このととは, 微 粒子径が大きい場合と小さい場合とでは，その滞留時間 分布関数が異なることを意味している. 平均径が $1 \mu \mathrm{m}$ の微粒子の場合, その排出速度は $0.001 \mathrm{~g} / \mathrm{s}$ 以下と極め て小さかった。

Table 1 亿示したように, $\mathrm{Al}_{2} \mathrm{O}_{3}$ 微粒子の場合, 平均 径が $6.3 \mu \mathrm{m}$ では $F R_{1}$ は 0.06 程度と小さく， 1 時間後には 供給した微粒子の $94 \%$ が排出している。また， $F R_{1}$ は平 均径の減少とともに増加する傾向を示した. 平均径が 1 $\mu \mathrm{m}$ では $F R_{1}$ が 0.941 と大きく, 乙の場合, 実用上層内 に蓄積されると判断したほうがよいと思われる。一方, 微粒子平均径と $\theta_{e}$ の関係は, 平均径が小さくなるほど $\theta_{e}$ が增加しており，前報 ${ }^{11}$ の結果と一致している. 平均粒 子径が $5 \mu \mathrm{m}$, 初期微粒子濃度が 0.005 亡同じ場合でも, $\mathrm{Al}_{2} \mathrm{O}_{3}$ の $\theta_{e 1}$ は $\mathrm{CaCO}_{3}$ のあのより 2 倍近くあ大きくなっ ており, 滞留時間は微粒子材料に依存するてとが分かる.

3) 排出微粒子の粒径分布の経時変化

Fig. 5 は $\mathrm{CaCO}_{3}$ を用いた場合の排出微粒子の粒径分 布の経時変化を示している. ての図より, 供給された微

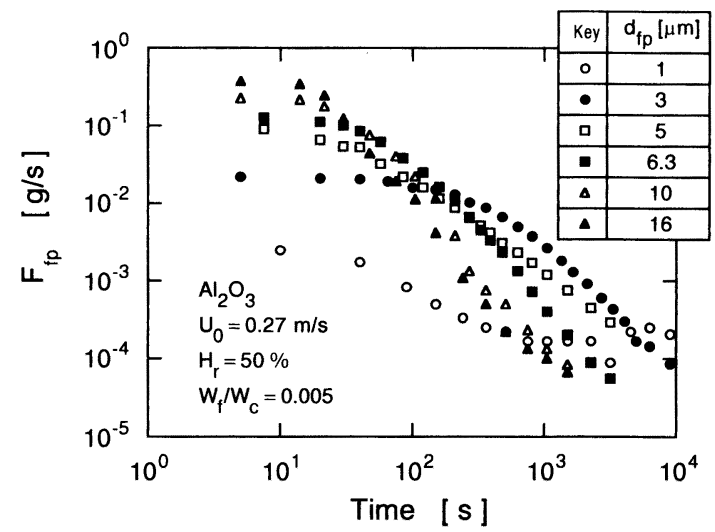

Fig. 4 Effect of average particle-size of fine particles on the elutriation rate of the fine particles

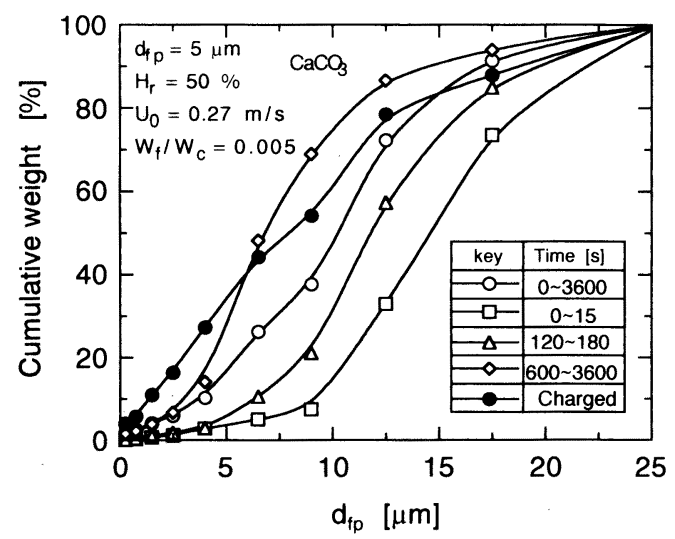

Fig. 5 Particle size distributions for the collected fine particles

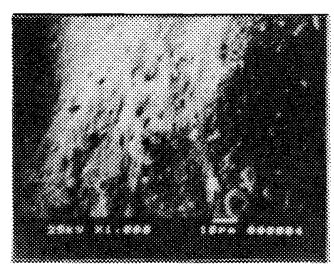

(a) 0 [s]

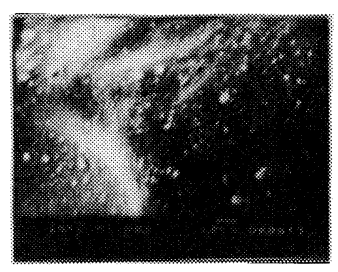

(c) $600[\mathrm{~s}]$

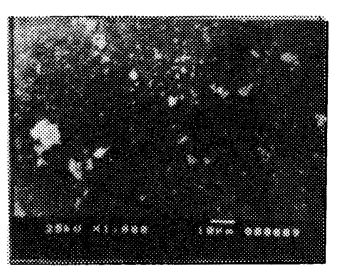

(b) $80[s]$

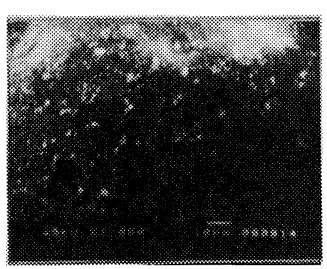

(d) $3600[\mathrm{~s}]$
Fig. 6 SEM photographs of fine particles $\left(\mathrm{CaCO}_{3}\right.$, $d_{f p}=5 \mu \mathrm{m}$ ) adhering on the surface of a coarse particle (activated alumina, $d_{c p}=400$ $\mu \mathrm{m})$ at different operating time 
粒子はその中であ大きな径の微粒子から順に排出される

ことが分る。Fig.6は 0s, 80s, 600s, 3600s 後に層内か

ら取り出した媒体粒子の表面のSEM 写真である.0sの

とき表面には $10 \mu \mathrm{m}$ 以下の様々な径の微粒子が付着して

いるが，それぞれ $80 \mathrm{~s}$ では $5 \mu \mathrm{m}, 600 \mathrm{~s}$ では $3 \mu \mathrm{m}, 3600$

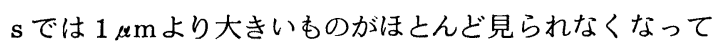

いる. 粉粒流動層における微粒子は媒体粒子上に付着し

て層内に滞留し, 大きい径の微粒子ほど滞留時間が短い

\section{ことがこれらの写真から裏付けられた。}

\section{結言}

1）供給された微粉体の中でも，径が大きい微粒子ほ ど層内滞留時間が短く, $1 \mu \mathrm{m}$ 程度の細かい微粒子はそ の多くが層内に残留する場合がある.

2) 層内微粒子濃度がある程度以上大きくなると, 初 ‘ 期排出速度が頭打ちになり，その結果平均滞留時間が大 きくなる傾向がある.

3）層内媒体粒子に付着する微粒子を確認した。

[ 謝 辞] 本研究の一部は文部省科学研究費の補助のも とに行われた，記して感謝する。

\section{Nomencla ture}

$d_{c p}=$ average diameter of coarse particles

$[\mu \mathrm{m}]$

$$
\begin{aligned}
& d_{f p}=\text { average diameter of fine particles }[\mu \mathrm{m}] \\
& F_{f p}=\text { elutriation rate of fine particles }[\mathrm{g} / \mathrm{s}] \\
& F R=\text { fraction of fine particles remained } \\
& \text { in the bed } \\
& H_{r}=\text { relative humidity } \\
& L_{m f}=\text { minimum fluidizing gas velocity } \\
& t=\text { time } \\
& U_{o}=\text { superficial gas velocity } \\
& U_{t}=\text { terminal velocity of particles } \\
& \theta=\text { mean residence-time }
\end{aligned}
$$

\section{Literature cited}

1) Kato, K., T. Takarada, M. Matsuo, T. Suto and N. Nakagawa: Kagaku Kogaku Ronbunshu, 17, 970-975 (1991)

\title{
The Fine Particles Residence in a Powder- Particle Fluidized Bed
}

\author{
Nobuyoshi Nakagawa, Jun Furukawa*, Takeshi Sato** \\ and Kunio Kato
}

\begin{abstract}
Dept. of Biological and Chem. Eng., Faculty of Eng., Gunma Univ., Kiryu 376
\end{abstract}

Key Words : Fluidized Bed, Fine Particle, Residence Time, Adhesion, Powder, Elutriation

Residence time distribution of fine particles in a powder-particle fluidized bed was measured by using batch feeding of the fine particles. The effects of the initial fine particle concentration and the size of fine particles on the residence time distribution and on the amount of fine particles remaing in the bed were described. When the initial fine particles concentration was greater than a definite critical value, the initial elutriation rate of fine particles remained constant and equal to a certain limit value. For particles as small as $1 \mu \mathrm{m}$, almost all fine partices remained in the bed after $1 \mathrm{~h}$ operation.

* Dainippon Ink and Chemicals Inc.

** Tone Jitsugyou High School 